\title{
Validation of the Arabic Childbirth Care Satisfaction Survey
}

Waleed Al Nadabi, ${ }^{1}$ Sahdia Parveen, ${ }^{1}$ Muhammad Faisal ${ }^{1}$ and Mohammed Mohammed ${ }^{1}$

${ }^{1}$ Faculty of Health Studies, University of Bradford, Bradford, United Kingdom (Correspondence to: Waleed Alnadabi: (alnadabizozo@yahoo.com).

\begin{abstract}
Background: Measuring maternal satisfaction in Arab countries is an essential indicator of care quality. However, existing surveys have limited psychometric properties and inclusion criteria.

Aims: To present the psychometric properties of the Arabic Childbirth Care Satisfaction Survey (CCSS).

Methods: The Arabic CCSS was developed from 2 English surveys. In 2017, 13 mothers assessed survey items in terms of clarity, importance and acceptability. The CCSS was distributed to all mothers who delivered a live baby during the 4-week study period in 9 hospitals in Oman. A sample of 461 participants was used for principal component analysis (PCA) and another sample of 408 participants (after removing missing data) was used for confirmatory factor analysis (CFA). Two-sample independent $t$ tests were conducted to establish discriminant validity. Stata software was used for the analysis.

Results: The survey demonstrated good face and content validity with all items rated above 3 out of 5 . Out of the 3566 targeted population, 958 (26.9\%) mothers participated. PCA identified 2 factors labelled as communication and control (Cronbach's $\alpha=0.90$ ) and care organization (Cronbach's $\alpha=0.68$ ) with good internal reliability. CFA demonstrated good model fit, confirming construct validity. Mothers who had vaginal delivery were more satisfied $(P<0.05)$ compared with those who underwent caesarean section, thus establishing good discriminant validity.

Conclusion: A short Arabic CCSS tool was developed. This new 10-item tool had good face and content validity, good internal reliability, construct validity and discriminant validity. It can provide valuable information to clinicians and decision-makers about the quality of maternity services.

Keywords: survey validation, Arabic, childbirth, maternal satisfaction, Oman

Citation: Al Nadabi W; Parveen S; Faisal M; Mohammed M. Validation of the Arabic Childbirth Care Satisfaction Survey. East Mediterr Health J. 2021;27(9):861-867. https://doi.org/10.26719/emhj.21.026

Received: 18/04/19; accepted: 24/01/21

Copyright $\odot$ World Health Organization (WHO) 2021. Open Access. Some rights reserved. This work is available under the CC BY-NC-SA 3.o IGO license (https://creativecommons.org/licenses/by-nc-sa/3.o/igo)
\end{abstract}

\section{Introduction}

Patient satisfaction is an essential measure of quality in health care that can be used for further improvement and research (1). Despite the extensive work related to maternal satisfaction with maternity care, there are few Arabic surveys available to measure satisfaction. There are 26 countries where Arabic is officially recognized by the government, with 18 having a majority of their people using it as their first language (2). A recent review by Hussein et al. (3) examined studies related to maternal satisfaction in the Middle East; however, they did not assess the quality of the surveys and focused instead on identifying components of satisfaction.

The systematic review by Sawyer et al. (4) found 9 instruments that can be used to measure satisfaction with care during labour and childbirth. They concluded that the Six Simple Questions (SSQ) and Patient Perception Score (PPS) are brief, easily administered, and have good reliability and validity. Although other tools included in their systematic review have high reliability and validity, they were lengthy, designed for a specific condition (e.g., caesarean section), or developed for a particular group of patients (uncomplicated vaginal deliveries with healthy born babies).
This paper presents the translation and validation of an Arabic survey to measure women's satisfaction with care during childbirth based on the SSQ and PPS. This survey will help clinicians and decision-makers to measure maternal quality of care as perceived by mothers.

\section{Methods}

\section{Survey development}

The survey items were devised by merging items from 2 validated English questionnaires, PPS and SSQ. The reason for merging the tools was to cover dimensions that were not covered by the other survey. The SSQ was developed by Harvey et al. (5) to measure maternal satt isfaction with childbirth at 48 hours and 2 and 6 weeks postpartum. As the name implies, the tool consisted of 6 questions that were scored on a 7-point scale. Two questions were negatively worded. The SSQ was found to have high reliability with Cronbach's $\alpha=0.86$. The PPS was developed by Siassakos et al. (6) to measure materr nal perceptions following operative childbirth. The questionnaire had 3 questions each measuring 1 dimension using a 5-point Likert scale. The dimensions measured were communication, respect and safety. The 3 items of the tool had good internal consistency with Cronbach's 
$\alpha=0.83$ and established face validity. Additionally, the authors reported that participants found it easy and simple to complete the questionnaire. After combining the 2 surveys, items 1, 2 and 3 were reworded, and 1 item was split into 2. The resulting combined tool, referred to as the Childbirth Care Satisfaction Survey (CCSS), had 10 items. Instead of the 5-point scale in the original PPS, 7 points were used to match the scales of the SSQ. Compared with the 5-point scale, the 7-point scale was believed to provide a more accurate and sensitive measure of a participant's evaluation (7). The survey had other items related to parf ticipants' educational level, employment status, number of babies in this delivery, number of previous deliveries, and type of delivery. Before finalizing the CCSS, the English version was translated into Arabic, validated and pilot tested. The following sections describe these steps in more detail.

\section{Translation of the tool}

The majority of participants were expected not to be fluent in English, hence the need for translation into the Arabic language (8). Compared with other techniques like forward-only translation, back translation is suggested to be the most reliable technique to avoid possible translation errors (9). In back translation, the original survey is translated into the target language and then translated back into the original language by another individual. In this study, the questionnaire was translated into Arabic by 2 researchers who were fluent in both languages. The translated version was then sent to a physician who was fluent in Arabic and English. The back-translated version was checked by the researcher and found to be consistent with only a few words that required amendment.

\section{Face and content validity of the Arabic questionnaire}

Once the tool was translated into Arabic, it was tested to determine face and content validity. Thirteen Omani mothers who had a previous delivery in Oman were contacted and requested to rate the survey items voluntarily. Mothers were asked to rate each question from 1 to 5 in terms of clarity, acceptability and importance. All survey items had an average score $>3$ in terms of clarity, importance and acceptability. The final English and Arabic translated versions of the SSQ and PPS can be seen in Appendixes 1 and 2.

\section{Study design and participants}

This was a descriptive cross-sectional study that was piloted in March 2017 in 1 hospital before including the remaining 9 secondary care hospitals that are under the umbrella of the Ministry of Health, Oman. All the included hospitals were certified by 1999 as baby friendly by the World Health Organization and United Nations Children's Fund (10). The whole study in the other hospitals was conducted from April to June 2017. The study targeted all mothers who gave a live birth (whether vaginal delivery with and without anaesthesia or caesarean section) during the study period (4 weeks in each hospital). Mothers who did not read Arabic were asked to get help from their attending relative (mother, husband, sister, etc.). If they had no relative to help them in completing the survey, they were excluded from the study. In Oman, institutions and staff are encouraged to ensure that a close relative/husband accompanies mothers so that they get the required support at delivery (11).

\section{Distribution and data entry}

The researcher gave questionnaires to the heads of quality departments in the participating hospitals who, in turn, gave them to the ward in-charge nurse for distribution to mothers. A distribution plan was provided to heads of quality departments to ensure consistency of distribution. As detailed in the plan, the surveys were handed to the mothers on their date of discharge (usually 36-48 hours after admission). Data were entered in a pre-prepared Microsoft Excel sheet by a coordinator who was trained in data entry, and the researcher double-checked $10 \%$ of surveys entered to ensure accuracy.

\section{Data analysis}

Data from the pilot hospital were included in the data analysis. Questions 3 and 6 were negatively worded and thus reverse coded. The 7-point Likert scale of responses ranged from strongly disagree (1) to strongly agree (7). The scales were used to measure the mean satisfaction score by adding the scores given by each respondent for each question and dividing by the number of respondents for that question. Similarly, the total satisfaction score was calculated by taking the average scores for all survey items for each hospital. Participants were considered satisfied if the mean score was above the midpoint response $(>4)$. Since 1 of the hospitals had only 4 participants, it was dropped from the analysis. Thus, the data presented here were confined to 9 hospitals with 958 mothers participating in the study.

The first sample of 461 participants was recruited from hospitals 1-4, and this sample was used to conduct principal component analysis (PCA) using StataCorp. PCA is an exploratory analytical tool to test the number of common factors influencing a group of measures (12). PCA was conducted using oblique (Oblimin) rotation to examine the internal structure of the CCSS and how each item contributed to the construct. The Kaiser-MeyerOlkin (KMO) test was used to assess sample adequacy where a value of $\geq 0.8$ represented a good sample size. Eigenvalues of $\geq 1$ were used to retain the factor and items were retained if they had a factor loading of $\geq 0.30$, as recommended by Field (13). Cronbach $\alpha$ was used to assess the internal reliability of the scale and the retained factors. As recommended by Pallant (14), an $\alpha$ value of 0.8, 0.7 and 0.6 indicated good, satisfactory and poor reliability, respectively.

Another sample of 497 women was recruited from hospitals 5-9. After removing missing data, 408 samples were used for confirmatory factor analysis (CFA) to examine the construct validity. CFA is another analytical tool to examine whether the factor model suggested by the PCA fits the observed group of data (12). Amos version 22 was used to assess the CFA using maximum likelihood 
estimation. Testing the model fit followed the guidelines of Hooper et al. (15) as follows: a ?2 to degree of freedom ratio $(\mathrm{CMIN} / \mathrm{DF}) \leq 2.0$, goodness of fit index $(\mathrm{GFI}) \geq$ 0.90, Comparative Fit Index $(\mathrm{CFI}) \geq 0.90$, standardized root mean square residual $(\mathrm{SRMR}) \geq 0.05$ and root mean square of approximation (RMSEA) $\geq 0.05$. Twosample independent $t$ tests were conducted to assess the discriminant validity where the null hypothesis was that there was no difference in the satisfaction score between vaginal and caesarean delivery. Statistical significance was set at $P<0.05$.

\section{Ethics, confidentiality and anonymity}

The Omani Ministry of Health approved this study. An information sheet was provided in front of the questionnaire to explain the purpose and importance of the study. The information sheet also emphasized that participation was voluntary and would not negatively affect the partic- ipants in any way in the future. To ensure confidentiality and anonymity, participants were not asked to provide any information that could identify them, such as name, identification number, address, or mobile number.

\section{Results}

\section{Respondents' characteristics and response rate}

Out of the 3566 targeted population, 958 (26.9\%) mothers participated in the study in the 9 hospitals, with a response rate of $18-79 \%$. The majority of respondents were not employed (67.2\%); had completed primary to tertiary level of education (62.7\%); did not have a chronic condition (87.7\%); this delivery was not their first (72.7\%); had a single baby (86.5\%); had vaginal delivery (70.1\%); and this was not their first delivery in the hospital (59.5\%) (Table 1). Participants in both samples had similar characteristics.

\begin{tabular}{|c|c|c|c|}
\hline Characteristics & Sample 1 N (\%) & Sample 2 N (\%) & Both samples N (\%) \\
\hline & 461 & 497 & 958 \\
\hline \multicolumn{4}{|l|}{ Education level } \\
\hline No education & $5(1.1)$ & $13(2.6)$ & $18(1.9)$ \\
\hline Primary/secondary/tertiary school & $284(61.6)$ & $315(63.4)$ & $599(62.7)$ \\
\hline Graduate/postgraduate & $168(36.4)$ & $163(32.8)$ & $331(34.4)$ \\
\hline Missing & $4(0.9)$ & $6(1.2)$ & $10(1.0)$ \\
\hline \multicolumn{4}{|l|}{ Employment status } \\
\hline Employed & $132(28.6)$ & $136(27.4)$ & $268(27.9)$ \\
\hline Not employed & $302(65.5)$ & $340(68.4)$ & $642(67.2)$ \\
\hline Retired & $5(1.1)$ & $3(0.6)$ & $8(0.8)$ \\
\hline Missing & $22(4.8)$ & $18(3.6)$ & $40(4.2)$ \\
\hline \multicolumn{4}{|l|}{ Do you have a chronic condition } \\
\hline Yes & $38(8.2)$ & $44(8.9)$ & $82(8.5)$ \\
\hline No & $400(86.8)$ & $440(88.5)$ & $840(87.7)$ \\
\hline Missing & $23(5.0)$ & $13(2.6)$ & $36(3.7)$ \\
\hline \multicolumn{4}{|l|}{ Is this your first delivery? } \\
\hline Yes & $126(27.3)$ & $107(21.5)$ & $233(24.3)$ \\
\hline No & $318(69.0)$ & $378(76.1)$ & $696(72.7)$ \\
\hline Missing & $17(3.7)$ & $12(2.4)$ & $29(3.0)$ \\
\hline \multicolumn{4}{|l|}{ No. of babies delivered } \\
\hline Single & $393(85.3)$ & $435(87.5)$ & $832(86.5)$ \\
\hline Twins & $8(1.7)$ & $10(2.0)$ & $18(1.9)$ \\
\hline Triplets or more & $37(8.0)$ & $35(7.0)$ & $72(7.5)$ \\
\hline Missing & $23(5.0)$ & $17(3.4)$ & $40(4.2)$ \\
\hline \multicolumn{4}{|l|}{ Mode of delivery } \\
\hline Vaginal & $310(67.3)$ & $361(72.6)$ & $674(70.1)$ \\
\hline Caesarean & $130(28.2)$ & $124(25.0)$ & $254(26.4)$ \\
\hline Missing & $21(4.6)$ & $12(2.4)$ & $34(3.5)$ \\
\hline \multicolumn{4}{|c|}{ Is this your first delivery in this hospital? } \\
\hline Yes & $193(41.9)$ & $170(34.2)$ & $364(37.8)$ \\
\hline No & $253(54.9)$ & $316(63.6)$ & $572(59.5)$ \\
\hline Missing & $15(3.3)$ & $11(2.2)$ & $26(2.7)$ \\
\hline
\end{tabular}




\section{Study 1: exploring the factor structure of the CCSS}

The factor structure of the CCSS was examined using a sample of 461 participants. The sample size was found to be adequate $(\mathrm{KMO}=0.883)$ to conduct PCA which suggested 2 factors with eigenvalues $>1$.o. Factors 1 and 2 explained $50 \%$ and $16 \%$ of the variance, respectively. Using a factor loading of $\geq 0.3,8$ items loaded onto factor 1 (laf belled as communication and control) and 2 items loaded onto factor 2 (labelled as care organization) (Table 2). Aln though item 5 (I felt involved in the procedures related to my care) did not reach the threshold eigenvalue, due to its theoretical importance and proximity to the threshold (0.29) it was kept in the survey. Factor 1 had Cronbach's $\alpha=0.90$, while factor 2 had a score of 0.68 , representing good internal reliability. As factor 2 had only 2 items, the average interitem correlation was explored and found to be 0.52 , which was above the optimum range of $0.2-0.4$ (16). This suggested that the 2 items were too closely ree lated.

\section{Study 2: testing the validity of the factor structure}

A separate sample of 408 mothers was used to test a 2 -factor model using maximum likelihood estimation. CFA showed that the data fitted the model well $\left(\chi^{2}(89)=56.26\right.$, $P<0.001 ;$ CMIN/DF $=2.16 ;$ GFI $=0.97$, CFI $=0.93$, SRMR $=0.06$ and RMSEA $=0.05$ ), thus demonstrating good construct validity.

\section{Discriminant validity}

A two-sample independent $t$ test using data from both samples was conducted and showed that the overall mean satisfaction score was significantly higher among those who had a vaginal delivery (5.4) compared with caes sarean delivery (5.3) $(t=2.10, P=0.036)$ (Table 3). Mean satisfaction score across all survey items (except Q8) was higher among mothers who delivered vaginally compared with women who had a caesarean section. However, this difference was significant in Q2.

\section{Discussion}

Currently, there are few Arabic surveys to measure maternal satisfaction in Arab countries, even though the majority of people in 18 countries use the Arabic language. This study aimed to address this gap by describing the psychometric properties of an Arabic survey developed by combining 2 existing tools to measure maternal satisfaction in 9 maternity units in Oman. The survey showed good face and content validity. The PCA showed that the new survey was based on adequate sample size and the 10 items loaded into 2 factors labelled as communication and control (7 items) and care organization ( 2 items). Both factors had good internal reliability with Cronbach's $\alpha=$ 0.90 for communication and control while care organization had a score of 0.68 . Measurement of CFA confirmed that the model fitted well and demonstrated good construct validity.

Additionally, the survey has good discriminant validity as shown by the 2-way independent $t$ test between mothers who had a vaginal delivery and those with caesarean section. Previous studies have suggested that women are more satisfied after vaginal delivery (including those with and without anaesthesia) compared with caesarean section $(17,18)$. The new scale was sensitive enough to pick up this difference and confirmed the finding of Mathew et al. (19) that Omani women prefer vaginal delivery.

The study had 2 main limitations. First, the study only had a $26.9 \%$ response rate. Nonetheless, the sample size $(n=958)$ made psychometric testing possible, as demonstrated by the KMO test. Second, the survey was given to mothers on their date of discharge (36-48 hours after delivery). Thus, the results might not be applicable to measurement of satisfaction 2 weeks or 2 months after delivery. Despite these limitations, we believe that the new tool has good psychometric properties and might be of some use in follow-up studies. Unlike other studies, we did not exclude complicated vaginal deliveries, making the results applicable to all deliveries. Although the new survey was tested in Oman only, the new CCSS could still be applied in Arab-speaking countries because it was

\begin{tabular}{|c|c|c|c|}
\hline Item & Variable & Factor 1 & Factor 2 \\
\hline 1 & I felt that I had adequate control over my care & 0.33 & \\
\hline 2 & The staff responsible for my care were caring and compassionate & 0.37 & \\
\hline 3 & Problems arose were not dealt with effectively & & 0.69 \\
\hline 4 & My needs have been addressed with appropriate consideration for my time & 0.35 & \\
\hline 5 & I felt involved in the procedures related to my care & 0.29 & \\
\hline 6 & The overall organization of my care has not been appropriate & & 0.69 \\
\hline 7 & I would choose the same type of care for my next pregnancy & 0.37 & \\
\hline 8 & I felt safe at all times & 0.38 & \\
\hline 9 & I felt well informed due to good communication & 0.34 & \\
\hline 10 & I felt I was treated with respect at all times & 0.38 & \\
\hline
\end{tabular}




\begin{tabular}{|c|c|c|c|c|}
\hline & & Caesarean section & Vaginal delivery & $P$ \\
\hline \multirow[t]{2}{*}{ All items } & $\mathrm{N}$ & 2445 & 6414 & $0.0357^{*}$ \\
\hline & Mean (SD) & $5.3(1.9)$ & $5.4(2.0)$ & \\
\hline \multirow[t]{2}{*}{ Q1 } & $\mathrm{N}$ & 243 & 639 & 0.3353 \\
\hline & Mean (SD) & $5.2(1.8)$ & $5.3(1.8)$ & \\
\hline \multirow[t]{2}{*}{ Q2 } & $\mathrm{N}$ & 250 & 658 & $0.0175^{*}$ \\
\hline & Mean (SD) & $5.7(1.7)$ & $6.0(1.6)$ & \\
\hline \multirow[t]{2}{*}{ Q3 } & $\mathrm{N}$ & 244 & 632 & 0.5207 \\
\hline & Mean (SD) & $3.4(2.3)$ & $3.5(2.4)$ & \\
\hline \multirow[t]{2}{*}{$\mathrm{Q}_{4}$} & $\mathrm{~N}$ & 242 & 637 & 0.3802 \\
\hline & Mean (SD) & $5.4(1.8)$ & $5.5(1.8)$ & \\
\hline \multirow[t]{2}{*}{ Q5 } & $\mathrm{N}$ & 240 & 617 & 0.0741 \\
\hline & Mean (SD) & $5.1(1.9)$ & $5.3(1.9)$ & \\
\hline \multirow[t]{2}{*}{ Q6 } & $\mathrm{N}$ & 242 & 639 & 0.1461 \\
\hline & Mean (SD) & $2.9(2.1)$ & $3.2(2.3)$ & \\
\hline \multirow[t]{2}{*}{ Q7 } & $\mathrm{N}$ & 244 & 638 & 0.3671 \\
\hline & Mean (SD) & $5.2(2.0)$ & $5.3(2.0)$ & \\
\hline \multirow[t]{2}{*}{ Q8 } & $\mathrm{N}$ & 246 & 648 & 0.6024 \\
\hline & Mean (SD) & $5.7(1.7)$ & $5.6(1.8)$ & \\
\hline \multirow[t]{2}{*}{ Q9 } & $\mathrm{N}$ & 245 & 649 & 0.0826 \\
\hline & Mean (SD) & $5.5(1.8)$ & $5.7(1.7)$ & \\
\hline \multirow[t]{2}{*}{ Q10 } & $\mathrm{N}$ & 249 & 657 & 0.077 \\
\hline & Mean (SD) & $5.8(1.7)$ & $6.0(1.6)$ & \\
\hline
\end{tabular}

*Statistically significant; $S D=$ standard deviation.

written in classical Arabic, which is the language spoken in formal communication and printed publications, with only minor differences among the Arab countries (20). This enhances our ability to generalize the CCSS, without the need for further modifications or corrections.

\section{Conclusion}

A short and easy to use Arabic CCSS to measure maternal satisfaction with the childbearing experience was devel- oped. This new 10-item tool has good face and content validity, internal reliability, construct validity and discriminant validity. It could provide valuable information to clinicians and decision-makers about the quality of maternity services.

Funding: This study was part of a PhD project that was funded by the Omani Ministry of Health but no specific funding was allocated to this study.

Competing interests: None declared. 


\section{Validation de l'enquête en langue arabe sur la satisfaction vis-à-vis des soins à l'accouchement}

\section{Résumé}

Contexte : La mesure de la satisfaction maternelle dans les pays arabes est un indicateur essentiel de la qualité des soins. Cependant, les enquêtes existantes ont des propriétés psychométriques et des critères d'inclusion limités.

Objectifs : Présenter les propriétés psychométriques de l'enquête de satisfaction vis-à-vis des soins à l'accouchement en arabe.

Méthodes : L'enquête en langue arabe sur la satisfaction vis-à-vis des soins à l'accouchement en arabe a été élaborée à partir de deux enquêtes en anglais. En 2017, 13 mères ont évalué les questions de l'enquête en termes de clarté, d'importance et d'acceptabilité. L'enquête a été réalisée auprès de toutes les mères ayant accouché d'un bébé vivant pendant la période d'étude de quatre semaines dans neuf hôpitaux d'Oman. Un échantillon de 461 participants a été utilisé pour l'analyse en composantes principales (ACP) et un autre échantillon de 408 participants (après suppression des données manquantes) a été utilisé pour l'analyse factorielle confirmatoire (AFC). Des tests t indépendants à deux échantillons ont été réalisés pour établir la validité discriminante. Le logiciel Stata a été utilisé pour l'analyse.

Résultats : L'enquête a démontré une bonne validité apparente et de contenu, avec un score supérieur à trois sur cinq pour tous les items. Sur les 3566 personnes ciblées, 958 mères $(26,9 \%)$ ont participé. L'ACP a identifié deux facteurs appelés communication et contrôle (alpha de Cronbach $=0,90$ ) et organisation des soins (alpha de Cronbach $=0,68$ ) avec une bonne fiabilité interne. L'AFC a démontré une bonne adéquation du modèle, confirmant la validité du construit. Les mères ayant accouché par voie basse étaient plus satisfaites $(p<0,05)$ que celles qui avaient subi une césarienne, établissant ainsi une bonne validité discriminante.

Conclusion : Un outil d'enquête de satisfaction brève en arabe sur les soins à l'accouchement a été mis au point. Ce nouvel outil qui comporte 10 items présente une bonne validité apparente et de contenu, une bonne fiabilité interne, une validité du construit et une validité discriminante. Il peut fournir des informations précieuses aux cliniciens et aux décideurs sur la qualité des services de maternité.

$$
\begin{aligned}
& \text { التحقق من استقصاء الرضا عن رعاية الوِلادَة في البلدان العربية }
\end{aligned}
$$

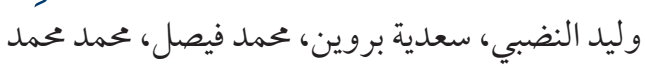

الخلفية: قياس الرضاعن رعاية الو لادة في البلدان العربية مؤشر أساسي لجودة الرعاية المقدَّمة للأمهات أثناء الو لادة. غير أن الدراسات الاستقصائية

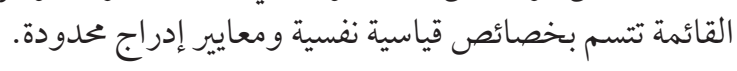
الأهداف: هدفت هذه الدراسة إلى القياس النفسي في استقصاء الرضا عن رعاية الو لادَة في البلدان العربية.

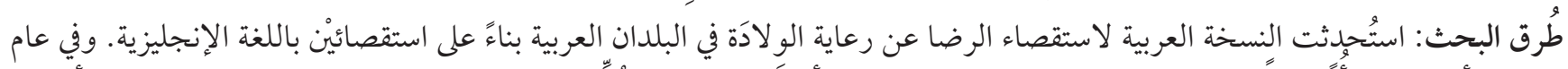

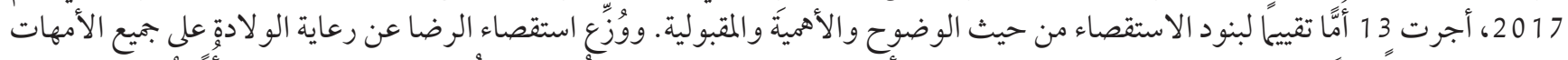

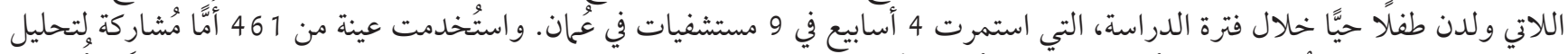

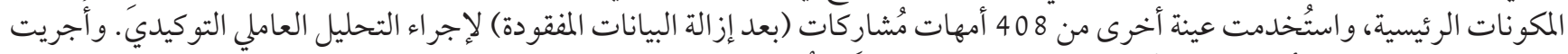

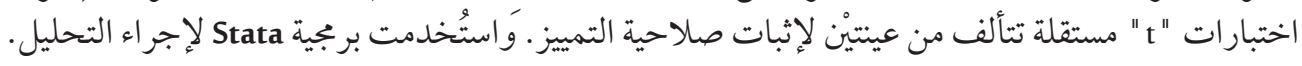

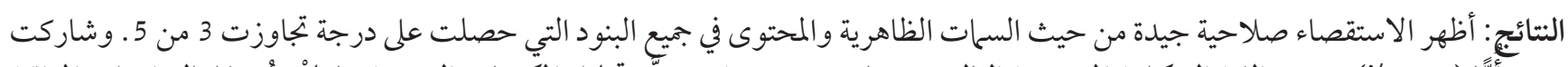

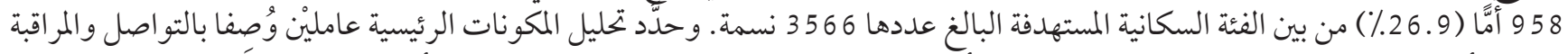

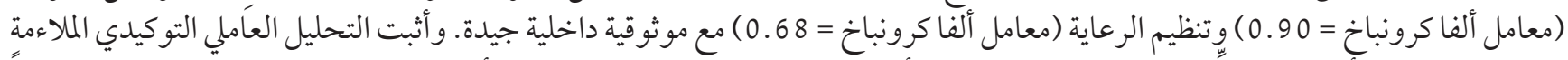

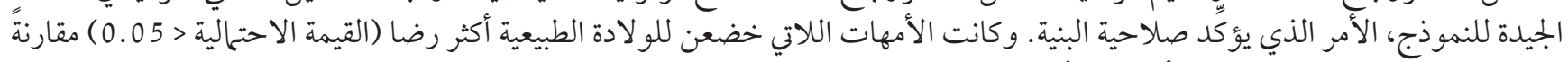

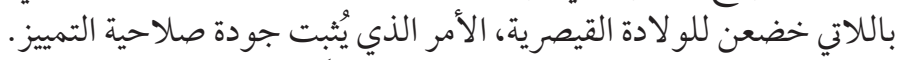

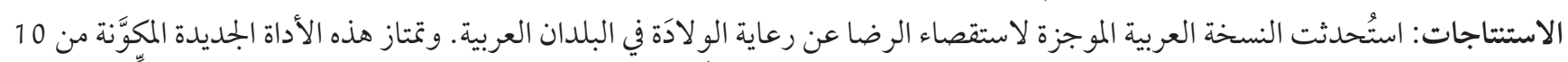

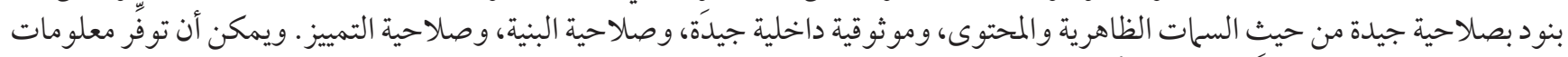

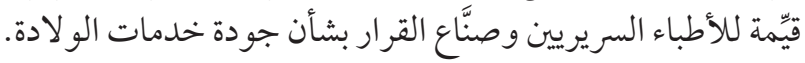




\section{References}

1. Beattie M, Murphy DJ, Atherton I, Lauder W. Instruments to measure patient experience of healthcare quality in hospitals: a systematic review. Syst Rev. 2015 Jul 23;4(1):97 https://doi.org/10.1186/s13643-015-0089-o PMID:26202326

2. Arabic speaking countries [website]. WorldAtlas; 2018 (https://www.worldatlas.com/articles/arabic-speaking-countries.html, accessed 28 April 2021).

3. Hussein S, Dahlen HG, Ogunsiji O, Schmied V. Women's experiences of childbirth in Middle Eastern countries: a narrative review. Midwifery. 2018 Apr;59:100-11 https://doi.org/10.1016/j.midw.2017.12.010 PMID:29421638

4. Sawyer A, Ayers S, Abbott J, Gyte G, Rabe H, Duley L. Measures of satisfaction with care during labour and birth: a comparative review. BMC Pregnancy Childbirth. 2013 May 8;13(1):1-10. https://doi.org/10.1186/1471-2393-13-108. PMID:23656701

5. Harvey S, Rach D, Stainton MC, Jarrell J, Brant R. Evaluation of satisfaction with midwifery care. Midwifery. 2002 Dec;18(4):2607 https://doi.org/10.1054/midw.2002.0317 PMID:12473441

6. Siassakos D, Clark J, Sibanda T, Attilakos G, Jefferys A, Cullen L, et al. A simple tool to measure patient perceptions of operative birth. BJOG. 2009 Dec;116(13):1755-61 https://doi.org/10.1111/j.1471-0528.2009.02363.x PMID:19775304

7. Finstad K. Response interpolation and scale sensitivity: evidence against 5-point scales. J Usability Stud. 2010;5(3):104-10.

8. McColl E, Jacoby A, Thomas L, Soutter J, Bamford C, Steen N, et al. Design and use of questionnaires: a review of best practice applicable to surveys of health service staff and patients. Health Technol Assess. 2002;5(31):256 https://doi.org/10.3310/hta5310 PMID:11809125

9. Maneesriwongul W, Dixon JK. Instrument translation process: a methods review. J Adv Nurs. 2004 Oct; 48(2):175-86 https://doi. org/10.1111/j.1365-2648.2004.03185.x PMID:15369498

10. Sinani MA. Breastfeeding in Oman - the way forward. Oman Med J. 2008 Oct;23(4):236-40. PMID:22334834

11. Pregnancy \& childbirth management guidelines level- 1. A guide for nurses, midwives and doctors (2nd edition). Oman: Ministry of Health; 2016 (https://www.moh.gov.om/documents/272928/4017900/ANC+Level+1+2nd+edition.pdf/2faec81b-46b3-7071-5d5f3a4a676089aa, accessed 28 April 2021).

12. DeCoster J. Overview of factor analysis. 1998 (http://www.stat-help.com/factor.pdf, accessed 28 April 2021).

13. Field A. Discovering statistics using IBM SPSS statistics (4th edition). Sage; 2013.

14. Pallant J. SPSS survival manual. A step by step guide to data analysis using IBM SPSS. McGraw-Hill Education (UK); 2013.

15. Hooper D, Coughlan J, Mullen M. Structural equation modelling: guidelines for determining model fit. Electronic J Bus Res Methods. 6(1):53-60. https://doi.org/10.21427/D7CF7R

16. Briggs SR, Cheek JM. The role of factor analysis in the development and evaluation of personality scales. J Personality. 1986 March;54(1):106-48. https://doi.org/10.1111/j.1467-6494.1986.tboo391.x

17. Geary M, Fanagan M, Boylan P. Maternal satisfaction with management in labour and preference for mode of delivery. J Perinat Med. 1997;25(5):433-9. https://doi.org/10.1515/jpme.1997.25.5.433 PMID:9438948

18. Guittier M-J, Cedraschi C, Jamei N, Boulvain M, Guillemin F. Impact of mode of delivery on the birth experience in first-time mothers: a qualitative study. BMC Pregnancy Childbirth. 2014;14:254. https://doi.org/10.1186/1471-2393-14-254.

19. Mathew, M., et al., Caesarean sections at Sultan Qaboos University Hospital: a three year review. J Sci Res Med Sci. 2002 Apr;4(12):29-32. PMID:24019723

20. Warschauer M, El Said GR, Zohry AG. Language choice online: globalization and identity in Egypt. J Computer-Mediated Commun. 2002;7(4):JCMC744 https://doi.org/10.1111/j.1083-6101.2002.tboo157.x 